\title{
Escrituras tóxicas: cuerpos y paisajes alterados
}

\author{
TOXIC WRITINGS: ALTERED BODIES AND LANDSCAPES
}

ESCRITURAS TÓXICAS: CORPOS E PAISAGENS ALTERADOS

\author{
Gisela Heffes *1 \\ gisela.heffes@rice.edu
}

\section{Resumen}

El presente artículo se enfoca en el reciente giro rural que ha dado la producción literaria argentina contemporánea. Remite a la noción de discurso tóxico propuesta por Laurence Buell (1988) para analizar dos narrativas: Distancia de rescate (2014), de Samanta Schweblin, y Las estrellas federales (2016), de Juan Diego Incardona, junto al poemario Un pequeño mundo enfermo (2014), de Julián Joven [seudónimo de Cristian Molina]. Se argumenta que, en estas escrituras, la toxicidad discursiva se articula a partir de la emergencia, cada vez más frecuente, del uso de agroquímicos en el campo argentino. Se plantea que, en esta pampa transfigurada, el cultivo de la soja transgénica metamorfosea el espacio en un paisaje contaminado $y$ contaminante cuyos agrotóxicos inoculan indiferenciadamente cuerpos humanos y no humanos. La representación tanto corporal como espacial se lee como una textualización que rediseña la relación entre sujeto y entorno natural (el campo) desplazando un discurso del "buen vivir" por una escritura de lo que propongo, tentativamente, como del "mal vivir". La producción estética aquí examinada apela a una reflexión desde la justicia ambiental que considere el inminente perjuicio y deterioro del paisaje contaminado.

Palabras clave: toxicidad, giro rural, espacialidad, cuerpos, literatura argentina

\begin{abstract}
This article focuses on the recent rural turn in contemporary Argentine literature production. It draws from Laurence Buell's notion of toxic discourse (1988) in order to analyze two narratives: Distancia de rescate (2014), by Samanta Schweblin, and Las estrellas federales (2016), by Juan Diego Incardona, along with the poetry collection Un pequeño mundo enfermo (2014), by Julián Joven [pseudonym of Cristian Molina]. With the emergence and more frequent use of agrochemicals on Argentine rural soil, I argue that these writings articulate a discursive toxicity anchored in a transfigured pampa. Furthermore, the cultivation of transgenic soy transforms the space into a contaminated and contaminating landscape, whose agrotoxicity inoculates indiscriminately both human and nonhuman bodies. I read these bodily and spatial
\end{abstract}

$1 *$ Universidad de Rice, Houston, EE.UU.

Tekoporá ${ }^{\circledR}$. Centro Universitario de la Región Este. Universidad de la República (C) Heffes. (2021)

Este es un artículo de Acceso Abierto distribuido bajo licencia Creative Commons (CC BY NC 4.0) 
representations, in both the fictions and poetry, as a textualization that redesigns the relation between subject and the natural environment, specifically the rural space, displacing a discourse of "buen vivir" for a literary production of what I propose, tentatively, as of "mal vivir" (bad living). This aesthetic production appeals to a reflection on environmental justice that considers the imminent damage and degradation of the contaminated landscape.

Keywords: toxicity, rural turn, spatiality, bodies, Argentine literature

\section{Resumo}

Este artigo concentra-se no recente virada rural que a produção literária argentina contemporânea deu. Refere-se à noção de discurso tóxico proposta por Laurence Buell (1988) para analisar duas narrativas: Distancia de rescate (2014), de Samanta Schweblin, e Estrellas federales (2016), de Juan Diego Incardona, juntamente com a coleção de poesias Un pequeño mundo enfermo (2014), de Julián Joven [pseudônimo de Cristian Molina]. Argumenta-se que, nesses escritos, a toxicidade discursiva se articula a partir do surgimento, cada vez mais frequente, do uso de agroquímicos no campo argentino. Sugere-se que, nesses pampas transfigurados, o cultivo da soja transgênica metamorfoseia o espaço em uma paisagem poluída e poluente cujos pesticidas inoculam indiferentemente corpos humanos e não humanos. A representação, tanto corporal quanto espacial, é lida como uma textualização que redesenha a relação entre o sujeito e o ambiente natural (o campo) deslocando um discurso de "bem viver" por uma escrita do que proponho provisoriamente como "mal viver." A produção estética aqui examinada apela a uma reflexão da justiça ambiental que considere o dano iminente e a deterioração da paisagem contaminada.

Palavras-chave: toxicidade, virada rural, espacialidade, corpos, literatura argentina 
If we alienate the living processes of which we are a part, we end, though unequally, by alienating ourselves.

Raymond Williams, "Ideas of Nature" (1980)

\section{El giro rural}

En los últimos años se viene produciendo una escritura cuyo espacio privilegiado es el campo. ${ }^{2}$ La pampa, espacio que alberga en el imaginario argentino desde debates sobre proyectos de constitución nacional, a tradiciones y herencias en disputa, adquiere, a comienzos del siglo XXI, los rasgos de un espacio reconfigurado y resemantizado. Algunos ejemplos de este fenómeno son las novelas La inauguración (2011) de María Inés Krimer, El viento que arrasa (2012) de Selva Almada, La omisión (2012) y Desmonte (2015) de Gabriela Massuh, Matate, amor (2012) de Ariana Harwicz, La vi mutar (2013) de Natalia Rodríguez, Distancia de rescate (2014) de Samanta Schweblin, Un pequeño mundo enfermo (2014) de Julián Joven [seudónimo de Cristian Molina], Las hamacas de Firmat (2014) de Ivana Romero, El rey del agua (2016) de Claudia Aboaf, y Las estrellas federales (2016) de Juan Diego Incardona, entre otros. La novela de Pedro Mairal, El año del desierto (2005), prefigura algunas cuestiones que se harán más visibles en la escena cultural argentina reciente. Me refiero, con esto, a cierta disolución de dicotomías clásicas que enfrentaban espacios e ideologías de manera antagónica, y acá pienso en Josefina Ludmer, y en sus islas urbanas. Pienso en que, desde el siglo XIX en adelante, el espacio de las ciudades constituye el locus clave para conjurar, expulsar la "barbarie", la que se ubica en el territorio rural, como aparece en un texto paradigmático como Facundo (1845), de Domingo Faustino Sarmiento. Esta disyuntiva cambia a finales del siglo XX y comienzos del XXI y, como sugiere Ludmer en su artículo "Territorios del presente. En la isla urbana" de 2004, la literatura actual es urbana, absorbe lo rural y se ha barbarizado. Si la ciudad se "barbariza", borrándose fronteras espaciales, asimismo el paisaje rural deviene un espacio ya no "salvaje" sino domesticado por el uso ilimitado del monocultivo, ya sea de la soja o del trigo, y por la práctica y el uso del suelo pampeano como laboratorio artificial donde la economía global y un estado en creciente desregulación interviene, objetivándolo. ${ }^{3}$

\footnotetext{
2 De los trabajos más recientes, vale la pena mencionar "El giro rústico: el nuevo campo argentino", de Fermín Rodríguez (2019), el cual propone rearticular la relación entre pasaje rural y la biología de los cuerpos que lo habitan.

${ }^{3}$ En "Campos que matan. Espacios, tiempos y narración en Distancia de rescate de Samanta Schweblin", Lucía de Leone (2017) lee "la pampa del monocultivo por tiempo ilimitado que remeda condiciones artificiales, de laboratorio, atentando así contra el equilibrio entre los organismos vivos y contra la refertilización de un suelo erosionado y seco" como un material "sobre el que ensayar y dar con formas narrativas" (pp.66-67).
} 
La protagonista de El año del desierto, María Valdés Neylan, narra su experiencia a lo largo de un año durante el cual Argentina es arrasada por un fenómeno extraño al que llaman la Intemperie. Se trata de un fenómeno cuya "cronología narrativa avanza (un año, desde el principio al final de la novela)" pero donde la Historia "insensiblemente 'retrocede", desde el "tumultuoso comienzo del siglo XXI" al siglo XVI, como señalan Juan Pablo Dabove y Susan Hallstead en la introducción a la nueva edición crítica (2012). Con la emergencia de este fenómeno regresivo, en el que el tiempo corre de manera inversa, la Intemperie llega "desde el fondo de la pampa" hasta rodear y avanzar "sobre el centro de la ciudad" (Dabove y Hallstead, 2012). Así, María se cruza con eventos, lugares y figuras del pasado mientras que aquellos símbolos de civilización y progreso, tan visibles al inicio del relato, comienzan a disiparse. ${ }^{4}$ Gracias a la Intemperie, "la ciudad va desapareciendo y el desierto va reconquistando" - como sugieren Dabove \& Hallstead-aquello que "fuera desde siempre suyo" (ix). Con esto me refiero, específicamente, a la disposición urbana de Buenos Aires, con su economía capitalista y una tecnología al servicio de las grandes corporaciones extranjeras. En estas condiciones, la protagonista tiene que luchar para sobrevivir ya que el ambiente que la rodea es cada vez más hostil y, conforme se va desarrollando el relato, María se encuentra sujeta a las inclemencias de la naturaleza y sometida a la voluntad de los hombres. ${ }^{5}$ No es casual, sin embargo, que a la transformación espacial le corresponda una alteración temporal. Como propuso Henri Lefebvre en su clásico La production de l'espace (1974), todo proceso de producción espacial implica una transformación de la historia, no tanto como una secuencia teleológica de eventos, sino como una serie de crisis y contradicciones de las relaciones sociales de producción, las que, a su vez, producen diferentes espacialidades y diversos modos de relaciones sociales. Es en este sentido que El año del desierto apuesta a una práctica crítica espacial cuya producción se hará evidente no sólo en sus transformaciones espaciotemporales, sino, a su vez, en muchas de las publicaciones posteriores.

Algunos trabajos críticos recientes, como el de Lucía de Leone (2017) y el de Dinorah Cossío $(2020)^{6}$, abordan la transfiguración del paisaje natural,

\footnotetext{
4 Cabe aclarar que al evocar nociones como "civilización" y "progreso" me estoy remitiendo a la idea eurocéntrica y decimonónica asociada posteriormente a conceptos tales como desarrollo (económico) y subdesarrollo.

5 Una novela como Las aventuras de la China Iron (2017), de Gabriela Cabezón Cámera, intenta justamente revertir este paradigma.

${ }^{6}$ En su tesis de doctorado, What Have I Done to Deserve This? "Abnormal" Motherhoods in 21st-century Spanish and Argentinian Cultural Products-defendida en diciembre de 2020 en la Universidad de Texas, Austin-Dinorah Cossío aborda algunas de estas cuestiones. En el tercer capítulo, “'Mamá, soy un monstruo': maternidad, toxicidad y neoliberalismo", analiza la novela Distancia de rescate (2014), de la argentina Samantha Schweblin, y la película Quién te cantará (2018), del director español Carlos Vermut, proponiendo que en estas dos obras las relaciones materno-filiales, influidas por políticas estatales neoliberales, se constituyen en formas de vínculo intoxicados "literal y simbólicamente" (p.39). Según Cossío, en el "contexto tóxico del campo argentino, la experiencia de la maternidad en la novela nos conduce a un espacio obsesivo y de ambivalencia afectiva que pone en cuestión la naturalidad y neutralidad de la figura de 'la buena madre"” (p.123). Así, el "discurso literario de
} 
específicamente el espacio rural, en uno atravesado por lo que Lawrence Buell definió como una discursividad tóxica (1998). Buell remite el origen del discurso tóxico contemporáneo a la novela de Rachel Carson, Silent Spring de 1962, cuyo primer capítulo, "A Fable for Tomorrow", introduce, en palabras de Buell, uno de los motivos discursivos claves para comprender esta idea de toxicidad: un pueblo en el corazón de Estados Unidos despierta un día a una primavera carente de pájaros e insectos. Se trata de un pueblo ficcionalizado pero que, para Carson, tiene su contrapartida no sólo en Estados Unidos, sino en cualquier otra parte del mundo: un espectro nefasto que se arrastra de manera inadvertida, tragedia que puede devenir una realidad brutal y de la cual urge tomar conciencia (Buell, 1998, p.645). Es sabido que la inventiva de Carson fue entonces contra el uso de DDT (Dicloro Difenil Tricloroetano), como así también otros pesticidas cuyos efectos tanto en la flora como en la fauna han dejado una marca indeleble. La recepción del trabajo de Carson fue inmediata. No sólo su libro vendió más de dos millones de copias, sino que hizo visible un problema que hasta ese momento no había sido planteado de manera directa y simple: si la humanidad envenena a la naturaleza, luego la naturaleza envenenará a la humanidad. ${ }^{7}$ Para Carson, tanto las acciones destructivas de los humanos como los descuidos frecuentes y cotidianos ingresan en los vastos ciclos de la tierra y regresan, a su turno, acarreando riesgos y peligros que amenazan tanto su salud y bienestar como sus existencias. El legado de Carson fue sin duda el de popularizar la ecología moderna.

Pero ¿cómo aparece entonces representado el campo, el campito, el paisaje rural, la pampa, en el régimen narrativo contemporáneo argentino? ¿Qué rasgos específicos emergen como correlato de la implementación de políticas neoliberales en un espacio que ha servido como repositorio simbólico de deseos y proyectos, sitio de polémicas culturales? Y, más aún, ¿qué aspectos adquieren los cuerpos que se desplazan por esta zona de borradura, esta zona de cruce e intersección, cómo es su fisonomía, de qué se componen? En el paisaje rural local, esta toxicidad discursiva a la que refiere Buell se articula a partir de la emergencia, cada vez más predominante, del uso de agroquímicos. En esta pampa transfigurada el cultivo de la soja transgénica metamorfosea el espacio en un paisaje contaminado y contaminante, cuyos agrotóxicos inoculan indiferenciadamente cuerpos humanos y no humanos. Cabe mencionar que la introducción de la agricultura transgénica en Argentina, aprobada en el año 1996, dio lugar a una expansión, sólo quince años más tarde, de 19 millones de hectáreas de campo argentino; y en 2012, cerca de 200 millones de litros de glifosato fueron utilizados para su fumigación-un volumen de casi 53 millones de galones, equivalente a 80 piletas de natación de tamaño olímpico (Lapegna, 2016, p.18). El uso de glifosato en el cultivo de soja transgénica es causante no sólo de problemas ecológicos y ambientales como la deforestación de

Schweblin" propone una "correlación entre el espacio contaminado y la transformación e intoxicación del vínculo materno-filial” (p.124).

7 Eliza Griswold, "How 'Silent Spring' Ignited the Environmental Movement" (The New York Times Magazine, septiembre 21 de 2012): http://www.nytimes.com/2012/09/23/magazine/how-silentspring-ignited-the-environmental-movement.html. Acceso obtenido el 31 de enero de 2021. 
bosques nativos, el desplazamiento violento de comunidades indígenas $\mathrm{y}$ campesinos locales, y la remuneración económica de una minoría privilegiada, sino también de salud pública y colectiva, dada la exposición de los habitantes a una toxicidad elevada y letal. La fiebre de la soja, en este nuevo "desierto verde", redefine, por lo tanto, la configuración del espacio rural, incorporando nuevas prácticas humanas, y funda, a su vez, un imaginario rural anómalo, el que, acosado por una pulsión economicista, desnaturaliza tanto al campo como a los cuerpos que lo habitan. ${ }^{8}$

En un artículo reciente sobre la guerra entre interespecies-en especial la soja y el amaranthus - Katarzyna Beilin y Sainath Suryanarayanan (2017) señalaron que la llamada soja Roundup Ready (RR) se encuentra genéticamente modificada para resistir, de manera expresa, al herbicida Roundup, manufacturado por la compañía Monsanto, y cuyo ingrediente activo es el glifosato. ${ }^{9}$ Este herbicida elimina toda planta indeseada con excepción del cultivo principal. El paisaje rural, por lo tanto, es intervenido por una soja modificada genéticamente, la que da lugar a un cultivo invulnerable, inmunitario, capaz de tolerar tanto a los insecticidas como a los herbicidas, los que refuerzan su intensidad en la medida en que el cultivo se vuelve más resistente. ${ }^{10}$ De esta forma, el paisaje alterado e intervenido, que va mutando a través de la progresiva extracción forestal, se abre paso hasta someter las "fronteras" arboladas o pobladas, impulsado por el cultivo transgénico que alimenta la demanda y consumo de los países industriales (Martínez Alier, 2002). Y con la transformación del espacio mutan, a su vez, los cuerpos, su materialidad, intoxicados por la acción inoculante que se esparce y se filtra a través del agua, la tierra y el aire.

\footnotetext{
${ }^{8}$ Ginya Truitt Nakata usa la imagen de "desierto verde" en un artículo publicado en The Nature Conservancy (febrero 28 de 2019), titulado "Monocultivos: la amenaza de los 'desiertos verdes' de hoy para la producción alimentaria de mañana". Allí la autora y ex directora de Tierras (América Latina) se refiere a estos espacios como "un ataque final a la Madre Naturaleza". Según explica, estos cultivos constituyen "una amenaza a largo plazo para la agricultura en sí" dado que el monocultivo crea una "espiral destructiva que agota los nutrientes del suelo, dejándolo débil e incapaz de soportar el crecimiento saludable de las plantas sin agregar cantidades cada vez mayores de fertilizantes sintéticos". Por otra parte, "crea nuevas oportunidades para las plagas, malas hierbas y enfermedades que un paisaje con mayor biodiversidad normalmente suprimiría por sí solo", lo que genera una necesidad de aplicar productos químicos cada vez más fuertes para combatirlas: https://www.nature.org/es-us/que-hacemos/nuestra-vision/perspectivas/monocultivosamenaza-desiertos-verdes-produccion-alimentaria/. Acceso obtenido el 1 de febrero de 2021.

${ }^{9}$ En el año 2015 la Organización Mundial de la Salud (WHO) dictaminó que el glifosato es "probablemente cancerígeno", confirmación que la comunidad científica ya había demostrado.

${ }^{10}$ En la crónica de investigación Envenenados. Una bomba química nos extermina en silencio (2017), Patricio Eleisegui señala que el "glifosato ejerce su acción herbicida a través de la inhibición de una enzima, enolpiruvil-shikimato-fosfato-sintetasa (EPSPS), impidiendo así que las plantas elaboren tres aminoácidos aromáticos esenciales para su crecimiento" (p.44). Este químico se caracteriza por no actuar de manera selectiva, dado que "elimina toda la vegetación", y es ésta la razón de "la manipulación genética que derivó en el desarrollo de la soja transgénica", ya que sólo la "incorporación del gen que resiste la potencia del glifosato permite a la oleaginosa continuar de pie y proseguir su crecimiento luego de las habituales fumigaciones" (p.44).
} 


\section{Naturaleza/Cultura}

La relación entre el mundo humano y no humano consiste en una relación inextricablemente vinculada a cosmovisiones y epistemologías variadas. Estas visiones a su vez se corresponden no sólo con un momento histórico específico, sino con una preocupación ecológica no siempre presente. Para un naturalista como Alexander Von Humboldt, la tierra consiste en un gran organismo viviente en el que todo se encuentra conectado, y a partir de lo cual se concibe una visión audaz del mundo natural que, como sugiere Andrea Wulf, influencia en cierta medida el modo en que comprendemos el mundo natural actual (2015). Dada su conceptualización y evaluación del territorio latinoamericano, el geógrafo y humanista prusiano fue, en particular, de gran influencia en lo que será la articulación entre naturaleza y la fundación de los estados nacionales (French \& Heffes, 2021, p.83). En Viaje a las regiones equinocciales del nuevo continente, resultado de sus travesías en América entre 1799 y 1804, Humboldt, junto al botanista francés Aimé Bonpland, proporcionaría una nueva interpretación científica a una idea vieja: el Nuevo Mundo, para el prusiano, se define como Naturaleza, una naturaleza, en palabras de Mary Louis Pratt "extraordinaria, dramática, un espectáculo capaz de un conocimiento humano y una comprensión abrumadores" (Pratt citada en French \& Heffes 2021, p.85 [mi traducción]). ${ }^{11}$ Esto no significa que Humboldt careciera de una fascinación por los instrumentos científicos, por los sistemas de medición y por los procesos de observación-sus Viajes se encuentran atiborrados de apuntes y bosquejos, descripciones de la flora, la fauna y los aspectos topográficos que encontrara a su paso, como así también de anotaciones, cálculos y especulacionespero la naturaleza, además de ser analizada y catalogada, debía ser protegida. Si el mundo natural es concebido como una red cuyos tejidos se encuentran interconectados, su vulnerabilidad es también "obvia": cada uno de los organismos que la componen funciona como un entramado conjunto $y$, de tensarse uno de sus hilos, el tapiz entero podría desmoronarse (Wulf, p. 5). Por esta razón, Andrea Wulf destaca que cuando en 1799 Humboldt visitó Venezuela y vio los efectos ambientales devastadores de las plantaciones coloniales en el Lago de Valencia (o Lago de Tacarigua), devino el primer científico que expuso los peligros de los cambios climáticos inducidos por la acción humana: la deforestación allí había dejado la tierra estéril, los niveles del agua en el lago estaban descendiendo, y con la desaparición de la maleza las lluvias torrenciales lavaron y empujaron la tierra que se encontraba en las laderas alrededor de las montañas (p. 5). Treinta años después, en 1829, el mismo Simón Bolívar advertiría sobre el peligro de la explotación de los bosques, destacando que "por todas partes hay un gran exceso en la extracción de maderas, tintes, quinas y demás sustancias, especialmente en los bosques pertenecientes al Estado, causándole graves perjuicios" (Bolívar, 1983, p.17).

La visión de Sarmiento (1945), no tan lejana en el tiempo, no sólo difiere, sino

\footnotetext{
${ }^{11}$ Ver específicamente la sección "Nature and the Foundation of the Nation-States", en The Latin American Ecocultural Reader (Jennifer French \& Gisela Heffes, 2020, pp. 81-86).
} 
que expone un proyecto ideológico que se aleja de la posición de Humboldt. Obsesionado con una agenda de índole nacional, Sarmiento intenta preservar el aspecto científico que vimos en Humboldt, pero descarta una sinergia entre el mundo natural y el mundo humano. Para el sanjuanino, el problema fundamental es que el espacio natural, el territorio rural de la campaña, carecía de res publica (1988, p. 71). Constituía, en la dicotomía decimonónica que había fundado, el espacio de la barbarie donde habitaba la "naturaleza salvaje" y, por lo tanto, el "llano inculto" (Sarmiento, p. 68). No existían allí, dirá Sarmiento, vestigios de civilización. Se trata, por el contrario, de un espacio gobernado por "el predominio de la fuerza, la preponderancia del más fuerte, la autoridad sin límites y sin responsabilidad de los que mandan", y la "justicia administrada sin formas y sin debates" (p. 63). Este espacio rural, en suma, que forja una genealogía literaria, histórica, cultural, la que regresa una y otra vez en el imaginario argentino ya sea como conjuro contra la civilización, como conjuro contra los inmigrantes, como conjuro contra la ciudad, o como acervo de una nostalgia y lamento por un pasado cada vez más inexistente (pienso, por ejemplo, en Don Segundo Sombra de Ricardo Güiraldes [1926]), será ahora el espacio en que se aloja una violencia diferente, invisible y lenta, que desestabiliza metáforas nacionales, proponiendo imaginarios alternativos y sin precedentes.

Si la disyuntiva civilización-barbarie tiene su correlato en el binomio culturanaturaleza, una lectura politizada, en clave ecocrítica, no sólo debe desafiar una posición dualista, sino facilitar una discusión en torno a lo que significa "naturaleza", sus definiciones, y la porosidad que impregna los presuntos antagonismos. Porque es justamente la dualidad cultura-naturaleza y sus consecuentes ramificaciones, en cuanto supone un marco de relaciones jerárquicas, asimétricas, unilaterales y carentes de reciprocidad, lo que se intenta poner en crisis. En cuanto postulación, es un intento por disolver esta división, entendiendo que remite y obedece a conceptos fundantes de Occidente, $\mathrm{y}$ al consenso generalizado de que la cultura se destaca por encontrarse "fuera" de la naturaleza.

Según Raymond Williams, cuando la naturaleza es separada de las actividades humanas, deja de ser naturaleza: disociación a partir de la cual los humanos se ven a sí mismos como productores y consumidores. Lo que para el autor del ya clásico The Country and the City (1973) consiste en la alienación de la naturaleza, la separación naturaleza / actividad humana no es sino una idea de naturaleza proyectada, formulada e inventada por los mismos humanos. ${ }^{12}$ Por esta razón, "naturaleza" es para el crítico británico uno de los conceptos más complejos, y una historia completa de los usos del vocablo implicaría una historia que comprenda una porción significativa del pensamiento humano. Será por eso que para el geógrafo Noel Castree (2013) la noción de "naturaleza" tiene más de pasado que de futuro. Idea que, ya en 1989, había sido proclamada por Bill McKibben, cuando anunciara "el fin de la naturaleza" a causa del impacto del cambio climático antropogénico en el planeta. Por su parte, otros críticos, enfocados en la "naturaleza humana" - es el caso de Fukuyama-advirtieron en el año 2002 que las

\footnotetext{
12 Raymond Williams, "Ideas of Nature", en Problems in Materialism and Culture (London: Verso, 1980, p. 80).
} 
biotecnologías como el splicing alternativo daría a lugar un futuro poshumano. Si bien hubo, y sigue habiendo, debates en torno a los alcances (y peligros) de definir la "naturaleza" como una construcción, aun cuando es imposible llamar a la "naturaleza" de manera irreflexiva como algo prístino, es importante subrayar que la materialidad del mundo físico fue desacreditada en función de algunos análisis y trabajos que intentan iluminar la "no naturalidad" de la "naturaleza". ${ }^{13}$ Ciertos neologismos permiten navegar esta necesidad de cuestionar a la "naturaleza" desde una perspectiva epistemológica mientras se respeta, a su vez, tanto la agencia como intransigencia física de aquellos fenómenos que produce. Un ejemplo es el término "naturacultura", concepto acuñado por la tecnocientífica Donna Haraway (1991, 2003, 2007), el que cuestiona la idea sui generis que remite a las esferas de lo "social" y lo "natural". En esta posición se inscriben Bruno Latour $(1993,2004)$, Neil Smith (1984), Andrew Ross (1995; 2011) y Timothy Morton (2007; 2010), para quienes lo que llamamos "naturaleza", en primer lugar, nunca existió. Lo que existió, en cambio, es una creencia socialmente efectiva de que las cosas "naturales" podían ser separadas y separables de las relaciones, instituciones y prácticas "sociales". ${ }^{14}$

Pero hablar de "naturaleza" es también hablar de ciudades, estos espacios construidos física y simbólicamente, y cuya materialidad se nutre de aquella. Si el campo sustenta a la ciudad, la ciudad consume al campo. Pensarlos como entidades separadas significa negar que un flujo, visible para algunos, invisible para otros, que se llama mercado, los conecta. La disolución del binario civilización-barbarie y, en términos más amplios, cultura-naturaleza requiere, así, de nuevas metáforas para pensar asociaciones, ensamblajes, relaciones y redes que conectan espacios y especies. La imagen de un hongo (Tsing, 2012) es adecuada para visualizar una red viviente que energiza las relaciones entre espacios, especies, tecnologías y artes, cuestionando la distribución de cuerpos (orgánicos e inorgánicos) según principios reguladores que categorizan territorios y definen los contornos donde estos cuerpos son, o serán, alojados. Inscrita en esta dinámica, una dinámica no exenta de tensión, la literatura actual registra, documenta y acomoda este fenómeno, reclamando nuevas imágenes, nuevos conceptos, nuevos cruces y fertilizaciones. Apela, desplegando poéticas diversas, a un lenguaje cuya potencialidad-y plasticidaddeje entrever un conjunto de prácticas, orientaciones y manifestaciones polucionantes, cuyas zonas de contacto y cruce disuelven viejas fronteras, como así también sus identidades más históricamente diferenciadas.

El presente artículo se enfoca en dos narrativas: Distancia de rescate y Las

\footnotetext{
${ }^{13}$ De ahí, es evidente, el reciente "giro ontológico". En el campo antropológico, este giro supone que si bien las ideas y perspectivas de los seres humanos acerca del mundo y otros objetos naturales y/o materiales pueden diferir, aquellos objetos (materiales y/o naturales) en sí mismos no varían-a la par de aquellas ideas. Como sugiere Paolo Heywood (2017): "la cultura puede diferir, pero la naturaleza no".

${ }^{14}$ Tanto el trabajo de Donna Haraway como el de Bruno Latour proponen una teoría de la naturaleza no dualista, lo que implica la no reducción a una realidad objetiva o a una subjetividad humana. Por su parte, Timothy Morton (2010) apela a una "ecología" sin límite, sin centro ni afuera, y desprovista de una esencia intrínseca (esto es, de naturaleza).
} 
estrellas federales, y en el poemario Un pequeño mundo enfermo; estas escrituras abordan la representación corporal como una textualización que rediseña la relación entre sujeto y entorno natural, el campo, el territorio rural, desplazando un discurso del "buen vivir" por una escritura de lo que prefiero definir, tentativamente, como del "mal vivir". Mientras que la noción de Buen Vivir es entendida como una postura biocéntrica, una búsqueda de nuevas semánticas enmarcadas en una transformación social-las que nacieron de procesos sociales que rechazan las políticas neoliberales de la creciente mercantilización que precariza la vida de millones de personas - y en la búsqueda de alternativas al discurso de desarrollo, donde "la idea de la naturaleza como sujeto de derechos que cuestiona el antropocentrismo fundante de nuestras sociedades" es vital, lo que estás narrativas revelan es que una ruralidad anclada a la noción de Naturaleza no adhiere necesariamente a estos postulados (Acosta, 2014, p. 9). ${ }^{15}$

Más aún, esta producción estética apela a una reflexión desde la justicia ambiental que considere el perjuicio y deterioro inminente de cuerpos tanto humanos como no humanos-esto es: animales y plantas, cuerpos orgánicos e inorgánicos-proponiendo que tanto en su degradación como en su mutación se alberga la frontera última del impacto antropogénico y catastrófico establecido, mediante una violencia sistémica y estructural, por la modernidad, uno que, a la mercantilización de la naturaleza le añade la objetivación corporal. Cuerpos y paisajes alterados.

\section{Mutaciones: cuerpos inóculos}

Distancia de rescate, de Samanta Schweblin (2014), narra la historia de Amanda y su hija Nina, quienes vienen de la ciudad a pasar el verano en el campo, y la de Carla y su hijo David, quienes residen en el espacio rural, donde David ha sido envenenado antes del presente de la narración, y cuya historia a través de Carla dispara la trama. No sólo David se ha contaminado por su contacto con el agua de un arroyo en el que, se presume, se desechan herbicidas y pesticidas, sino que los envenenamientos ocurren con frecuencia, apropiándose en el texto del cuerpo de Amanda y de su hija Nina. El diálogo con David, que abre el relato en la primera página, describe los efectos del veneno como "gusanos", esto es, una sustancia invisible que experimentan los residentes del pueblo: "gusanos, en todas partes" (p. 11). El cuerpo de Amanda, recostado, tendido, es un cuerpo inmovilizado y que no responde. Como el de los caballos, los patos, el perro, u otros animales de los alrededores, el cuerpo de Amanda se inserta en un campo "rodeado de sembrados", en cuyo pueblo los niños se concentran en una salita de espera de un hospital precario, sin médicos, para recibir atención en un momento en que ya "[n]o pueden escribir" porque "no controlan bien sus brazos [...] su propia cabeza, o tienen la piel

\footnotetext{
${ }^{15}$ Utilizo aquí la mayúscula para hacerme eco del trabajo de Eduardo Gudynas, quien sostiene que la utilización del término Naturaleza en mayúscula implica una cuestión mucho más trascendental que la mera cuestión nominativa. En Derechos de la naturaleza (2014), Gudynas promueve una postura biocéntrica que concibe a la Naturaleza como sujeto político, esto es, como una entidad idónea para recibir derechos políticos. En esa misma línea se la califica de "sujeto ético", en cuanto sujeto "otro" que interpela y cuestiona.
} 
tan fina que, si aprietan demasiado los lápices, terminan sangrándoles los dedos" (p. 86). En esta historia de cronologías intercaladas, pesticidas como diazinón y malatión, y herbicidas como glifosato, franquean las fronteras que separan organismos vivientes, y se introducen en los cuerpos humanos y no humanos a través de los canales vitales para la sobrevivencia (el aire a través de las fumigaciones, el agua en los desagües de químicos en los arroyos, y el pasto que contiene y absorbe los rocíos diarios), alterando las fisonomías corporales, el paisaje, y el entorno natural, desnaturalizándolos: allí los "chicos son extraños", muy pocos nacen sanos, y la mayoría tiene deformaciones: "no tienen pestañas, ni cejas, la piel es colorada [...] y escamosa también” (p. 108).

El cuerpo de David, a pesar de ser tratado por una curandera local, devienesegún el relato-una "monstruosidad". Una aberración causada por la máquina implacable e invisible de un biocapitalismo salvaje-y nótese que aquí es dónde se alojaría lo "salvaje", y ya no en la "naturaleza" sarmientina-que empuja de manera indiscriminada humanos y no humanos hacia un abismo de mutaciones y cuerpos poseídos. Cabe aclarar que utilizo el concepto de "biocapitalismo" según lo emplea Kelly Fritsch (2017) en un artículo sobre embarazos tóxicos, en referencia a la economización de la vida, y en tanto discurso acerca de las vidas con mayor o menor valor en términos económicos más que exclusivamente biológicos. Para Fritsch, los riesgos relacionados con la exposición a químicos son a su vez biológicos y económicos, y su impacto afecta tanto el presente como el futuro especular (p. 368).

En la novela corta de Juan Diego Incardona (2016) los "mutantes"—así son llamados desde el comienzo - forman parte de una casta circense que habita la provincia de Buenos Aires. Mientras la historia transcurre en el pasado (comienza en el año 1989) apela, por otra parte, a un futuro apocalíptico: es un relato "que tiene algo futurista o distópico o de ciencia ficción típicamente argentina", un mundo "pos apocalíptico de descarte, de ruinas" ("Hoy estamos"). La novela alu de al "fenómeno" que, como "la Intemperie" en Mairal o los "gusanos" en la novela de Schweblin, ocurre de manera imprevista, aunque "[n]o se sabe si las semillas ya estaban esparcidas desde antes o si el viento matancero las levantó, desterrándolas del campito", creando las condiciones favorables para que una plaga de poinsettias, o estrellas federales, cubran la vasta zona de Villa Celina "con un rojo furioso" o "punzó" (pp. 21-22). Este espectáculo apocalíptico de fertilizaciones previsibles no sólo anuncia la presencia esperada de un "hongo nuclear", sino además la llegada de las "criaturas más fantásticas del mundo", el "Circo de las Mutaciones" (pp. 22-23). Es importante señalar que el fenómeno al que alude el narrador "se produjo en 1989”, año clave en cuanto se inicia la presidencia de Carlos Saúl Menem, quien inauguró en Argentina-como bien se sabe-una política neoliberal basada en ajustes económicos, desregulaciones, y una relación obsecuente con el Fondo Monetario Internacional en Washington DC. ${ }^{16}$ Durante la emergencia del

\footnotetext{
${ }^{16}$ En el relato las referencias al peronismo atraviesan la historia desde el comienzo hasta el final, conformándose así en una marca indeleble no solo de este texto sino de la producción literaria de Incardona. La presencia del peronismo y, en terminos específicos, "la patota menemista" como
} 
"fenómeno", el narrador protagonista busca refugio bajo la carpa del Circo, y es allí donde consigue empleo trabajando para el Hombre Regenerativo de La Tablada: un hombre que se corta sus propios miembros, los cuales le vuelven a crecer como si nunca los hubiera perdido. Otros mutantes habitan el circo, como, por ejemplo, la Mujer Lagartija "con su cola larga y puntiaguda", los Infracaballos, "dos equinos del tamaño de hormigas", y el Petiso Orejudo, entre muchos más (pp. 23-24). No sólo las referencias al peronismo abundan, sino que la historia argentina, la historia social y económica, pero también la historia literaria y cultural, entretejen la trama como fantasmas que regresan porque en realidad, jamás se han ido. Hay en el relato un juego de ambivalencias donde el rojo "punzó" de las poinsettias (mejor conocidas como "estrellas federales") articula una serie de relaciones emblemáticas: por un lado, el rojo remite a "sangre", "fuego" y "carne viva", elementos que de forma conjunta evocan el desastre ecológico causado por el "fenómeno":

[E]xplotaban hongos químicos sobre la Matanza, rompiendo bielas, pistones y cojinetes, desatándose correas y engranajes para finalmente derrumbarse y caer, en bloques de hierro y fundición, sobre nuestras casas, nuestras escuelas, nuestras iglesias y nuestros clubes. (p. 56)

Por el otro, el rojo "punzó" apela a un símbolo decimonónico que definió al partido federal, liderado por Juan Manuel de Rosas, el cual-no es coincidencia-fuera el enemigo acérrimo de Sarmiento. Así, esta amplia serie de metáforas puede leerse en varios niveles y de diversos modos, aunque, sin duda, la ironía y el sarcasmo prevalecen como crítica discursiva. ${ }^{17}$

En Las estrellas, el desastre ambiental se vuelve devastador con la llegada de una lluvia de ácido sulfúrico. Con explícitas referencias a "la lluvia de fuego" de Leopoldo Lugones en su cuento homónimo, las "nubes saturadas de dióxido de azufre", y que forman "arcoíris petroquímicos", acechan el conurbano bonaerense derritiendo a su paso casas, parques, personas y animales (p.55). ${ }^{18}$ La catástrofe tiene un origen claro: se trata de "gases escapados de los depósitos sin mantenimiento, de los tanques abandonados por las empresas, de las fugas del cementerio de fábricas", es decir, de los desechos industriales que han sido parcialmente desmantelados, y que transforman a las poblaciones aledañas en "sociedades del riesgo", como las definió el sociólogo alemán Ulrich Beck (1986).

\footnotetext{
"representante de la violencia del liberalismo de los 90 que atenta contra el peronismo auténtico", fue analizada ampliamente por Sandra Contreras (2011).

${ }^{17}$ Sin embargo, al tratarse de una saga cuyo locus narrativo es Villa Celina (El ataque a Villa Celina [2007], Villa Celina [2008], El campito [2009] y Rock barrial [2010]), estas metáforas de mutaciones pueden leerse según la explicación e hipótesis planteada por Incardona en la introducción misma: “[c]omo muchos cuentos de Villa Celina transcurren en los noventa, pre-2001, creo que allí está la explicación de por qué los relatos rompen con el realismo y se convierten en historias fantásticas donde aparecen fantasmas, monstruos y mutantes. Toda la época es una gran metamorfosis" (2016, p.13).

${ }^{18}$ El cuento "La lluvia de fuego" de Leopoldo Lugones fue publicado en el libro Las fuerzas extrañas (1906).
} 
Para Beck, en la modernidad avanzada la producción social de bienes es sistemáticamente acompañada por la producción social de riesgos. Por lo tanto, los problemas y conflictos relacionados con la distribución en una sociedad de la escasez se yuxtaponen con los problemas y conflictos que surgen de la manufactura, asignación y repartición de los riesgos producidos de forma tecnológica y científica (Beck, 2004, p.19). No es de sorprender, entonces, que en las sociedades del riesgo, tanto lo imprevisible como los efectos inadvertidos devengan una fuerza dominante tanto histórica como social (p.22).

La disparidad entre la producción social de bienes y su reverso, la producción social de riesgos refuerza la idea de que el biocapitalismo neoliberal tiene consecuencias, como sugiere Kelly Fritsch (2017), en cómo pensar de manera conjunta toxicidad y corporeidad. Más aún, si representación corporal implica a su vez parálisis y discapacidad. Los neurólogos Philippe Grandjean y Philip J. Landrigan (2014) analizaron los efectos de la exposición tóxica en el comportamiento y desempeño neurológico desde la niñez, demostrando la correspondencia entre distribución de bienes y riesgos, como así también la cuestión respecto a qué poblaciones-y cuáles no-se debilitan en función de aquella. Aunque su investigación se basa en Estados Unidos, el problema de distribución $y$ debilitamiento poblacional consiste en un fenómeno similar (sino peor) en el ámbito de América Latina y, más específicamente, el de Argentina. La falta de estándares y leyes que regulen la producción de sustancias químicas, como la distribución y exposición ambiental a determinadas partículas tóxicas, puede tener efectos nocivos a largo plazo, exacerbando la incapacidad de funcionamiento en todo aquello expuesto a su toxicidad (Fritsch, 2017, 360). Si en Distancia la discapacidad se traduce en la inmovilidad de Amanda, quien yace postrada, como así también en la ceguera de los personajes contaminados ("todo está tan blanco" [p.109]"), en las deformaciones (la "nena de la cabeza gigante" [p.108]) o, incluso, en el "dolor de cabeza", las "náuseas", las "úlceras de la piel”, los "vómitos con sangre” y los "abortos espontáneos" (p.23), en Las estrellas, el efecto de parálisis es visualmente más violento: en cuánto a lo subjetivo, es "la estampa de un hombre quemándose vivo" (p.56); en términos espaciales, es la desaparición consecuente del conurbano bonaerense (el "campito"), cuya existencia concluye tras el éxodo de los sujetos desmembrados por los efectos de la lluvia de ácido sulfúrico:

La comunidad caminaba al sudeste hasta que se le caía la piel, la carne, los huesos, y ya no quedaba nada para la fuerza de gravedad: en matrimonio con la nada, el conurbano se derretía a la hora del reloj de plastilina. (p.84)

En Distancia de rescate, el marido de Amanda regresa a la ciudad, dejando a sus espaldas el campo, y sin mirar atrás, queriendo quizá borrarlo de su memoria para siempre:

No ve los campos de soja, los riachuelos entretejiendo las tierras secas, los kilómetros de campo abierto sin ganado, las villas y las fábricas, llegando a la ciudad. No repara en que [...] hay demasiados coches, 
coches, y más coches cubriendo cada nervadura de asfalto. Y que el tránsito está estancado, paralizado desde hace horas, humeando efervescente. (p.124)

Como En el año del desierto, las novelas de Schweblin e Incardona apelan alegóricamente a un fenómeno que acecha a los personajes, arrasando con él los contornos espaciotemporales que dividen, fragmentan y clasifican orígenes, clases, géneros, razas. Un fenómeno cuya escala escapa fronteras tradicionales, podríamos decir, fronteras modernas.

Del mismo modo, el poemario de Julián Joven (2014) alude a otro "fenómeno": esta vez, el "Mal". Se trata de un poemario que, en efecto, dialoga oportunamente con las novelas de Schweblin e Incardona. Con el primer poema se inaugura una correlación ineludible entre espacio rural, cuerpo y toxicidad:

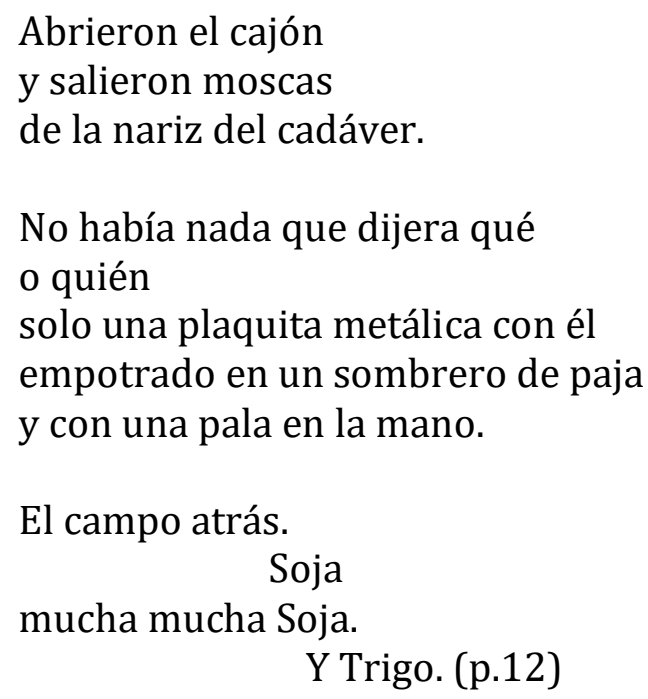

El "pequeño mundo enfermo" al que alude el título es un mundo donde el cáncer, el asma y otras enfermedades asociadas a la producción agrícola y el uso de agroquímicos van apropiándose de los personajes, tejiendo otro entramado, el de una discursividad tóxica, para volver visible lo que para muchos yace en el olvido o en la oscuridad. En una entrevista poco tiempo después de la aparición de su libro, Cristian Molina referió al cáncer "metafórico y literal" que se encuentra cada vez más presente, "sobre todo en los pueblos, o en el campo, espacios que ya no están tan alejados de la ciudad en ningún sentido", y señaló que son éstos "los mismos espacios que, también hasta hace poco, parecían haber desaparecido de las agendas de escrituras contemporáneas, absorbidos por la eminente presencia e intereses en el espacio urbano" ("Esa idea"). Según Molina, "hay quienes siguen viviendo en pueblos o en el campo en el siglo XXI", y hay allí "malestares que los atraviesan también, que no son ya los del corral decimonónico o de inicios del siglo XX: el crecimiento inaudito de las tasas de cáncer es uno de ellos y es también uno de los malestares de nuestra cultura-aunque no el único" ("Esa idea").

El poemario deja hablar a un Julián Joven que registra esas altas "tasas" en la materialidad de los cuerpos (el pá, la má, la tía, pero también el caballo, y muchos 
muertos, y moscas, y gusanos). Como en Distancia, el "caballo apareció reventado en medio de las vías" y en su interior los veterinarios encontraron "una pasta verde / idéntica a la de las chinches" (p.37). Pero el pequeño mundo, en el poemario, es un mundo en expansión, una enfermedad que acecha y abarca poblaciones enteras, y quienes sufren a diario sus efectos deben "correr" para evitar la intoxicación:



Las mujeres corren "desesperadas dentro de la casa", con miedo, ya que "las partículas vaporosas", y alguna "semilla pelada", se les iba "a meter adentro" (p.75). El veneno, alojado presuntamente en la semilla de soja transgénica (rociada además por el glifosato), permea el cuerpo a través del aire, ese mismo aire que intoxica al pá, "atacado sin respiración en pleno asma", y quien intentaba "aspirar el aire fresco" mientras que, de fondo, "se oían los motores [...] de las cerealeras en la madrugada" (p.29).

En Las estrellas, la toxicidad del aire adquiere también cierta ubicuidad: "un sol contaminado despidiendo luces hacia el espacio, cargadas de venenos químicos" de manera que "en las orillas de otras cuencas y riachuelos" las "plantas hicieran fotosíntesis de nuestros desechos" (Incardona, 2016, pp.70-71). El principio ecológico que caracteriza el ecosistema, es decir, la cadena de relaciones que conecta a los elementos entre sí y que fuera notablemente descrita por Humboldt, revela en estos relatos (narrativos y poéticos) que la disyuntiva decimonónica que enfrentaba civilización frente a barbarie, reemerge bajo una forma nueva, ya no inversa, ya no enfrentada como un binomio, sino yuxtapuesta. Si la crisis ecológica es una crisis transespacial, transnacional y transcontinental, las narrativas contemporáneas argentinas dejan entrever un discurso tóxico que impugna estigmatizaciones tradicionales para ofrecer, en su lugar, estigmatizaciones corporales nuevas: sea el estigma de la enfermedad, sea el estigma de la deformidad, sea el estigma de la monstruosidad. ¿Cómo definir, entonces, esta producción estética? ¿En qué genealogía inscribirla? ¿Cómo definir su lenguaje? En primer lugar, me gustaría postular que estas expresiones estéticas producen un lenguaje tóxico, un lenguaje que se ciñe a un "fenómeno" material, apenas perceptible, pero que permea el espacio y los organismos que lo habitan, transformándolos en fantasmagorías, espectros, remanentes de vida. En segundo lugar, quisiera proponer que estas semióticas tóxicas componen un lenguaje que entreteje, como capas contaminantes, una forma tangible de escritura, una textualidad que descentra y desestabiliza nociones dicotómicas, dualidades que enfrentan cultura-naturaleza, ciudad-campo, sujeto-objeto, mundo humano-no humano. 


\section{Ecologías discapacitadas}

La artista e investigadora Sunaura Taylor (2019) señaló, recientemente, cómo la creciente polución produce discapacidad, cuestionando los supuestos de que ciertas poblaciones tienen más predisposición a enfermarse (que otras). Supuestos que, como ya mencioné, se corresponden con un biocapitalismo que determina, posiciona y distribuye no sólo riesgos sino patologías y parálisis. Las distintas vertientes descritas aquí se identifican con lo que Taylor definió como una ecología discapacitada. Esto es, la red de discapacidades que se crean espacial y temporalmente, y que atraviesan fronteras de especies cuando los ecosistemas se encuentran contaminados, vaciados, y profundamente alterados. Una ecología discapacitada se corresponde, así, con las formas materiales y culturales en que la discapacidad se manifiesta y es producida entre entidades humanas y no humanas. ${ }^{19}$

Las imágenes documentadas por el fotógrafo argentino Pablo Ernesto Piovano apuntan a esas formas. En el mismo año en que Schweblin y Joven publicaran sus textos, Piovano propuso crear un registro visual de los efectos corporales en aquellas personas que estuvieran en contacto directo con los agroquímicos. Para esto, se embarcó en tres viajes que abarcaron 15.000 kilómetros de sembrados en Argentina y que dieron, como resultado, El Costo Humano de los Agrotóxicos, un documental de menos de diez minutos en el que Piovano cuestiona, además, el silencio establecido en los medios de comunicación, los cuales omiten las consecuencias de las fumigaciones en los cuerpos de las poblaciones aledañas ("The Human Cost"). ${ }^{20}$ Las fotografías revelan un espacio degradado, el que constituye discapacidad, y documentan, asimismo, cómo los cuerpos de las ecologías discapacitadas moldean el paisaje y su entorno. Las imágenes, por lo tanto, invierten la invisibilidad lenta y destructiva de una toxicidad que se resiste a ser capturada por la mirada, aunque su continua utilización, impalpable o presuntamente inmaterial, penetra la materialidad de los cuerpos, todos los cuerpos, hasta reemerger como una distorsión física y visible, una evidencia irrefutable. Son imágenes que, sin intentar ser morbosas, fluctúan entre el horror y lo surreal. Y, en este sentido, conforman una semiótica visual tóxica enmarcada por una materialidad escatológica.

A través de diferentes técnicas, como el blanco y negro, y el marcado contraste, las fotografías visualizan una exposición a lo que Stacy Alaimo (2016) definió como el "mundo material amplio", el cual es penetrado por todo tipo de sustancias y elementos que pueden ser (o no) capturados (p.4). Resulta paradójico, entonces que, a pesar de ser prácticamente impalpables, las sustancias se desarrollan y crecen hasta emerger en los cuerpos como una protuberancia, transformando la invisibilidad de las fumigaciones en una realidad inequívoca, material y concreta. La exposición de los cuerpos a los agroquímicos conlleva un

\footnotetext{
${ }^{19}$ Ver Sunaura Taylor (2019) “Disabled Ecologies: Living with Impaired Landscapes”, charla que tuvo lugar en The Othering and Belonging Institute en UC Berkeley.

20 Según el documental se utilizan 370 millones de productos agroquímicos por año, y este hecho pasa inadvertido entre la opinión publica: https://www.lifegate.com/people/news/the-human-costof-agrotoxins-glyphosate.
} 
"estado de total desprotección" similar a aquellos expuestos a detonaciones nucleares, y analizados por Adriana Petryna en Life Exposed: Biological Citizens After Chernobyl (2002). La inmaterialidad de los efectos lentos y corrosivos de los agroquímicos nos recuerda aquello que Ursula Heise (2008) definió como "espacios de riesgos" (riskspaces). Las toxinas químicas son decisivas para este tipo de riesgo dada su condición de agentes que borran, efectivamente, "las fronteras entre cuerpo y espacio, entre esferas domésticas y públicas, y entre tecnologías beneficiosas y dañinas" (p.177). Timothy Morton, por su parte, acuñó el término hiperobjetos (Hyperobjects, 2013) para referir a aquellos objetos que por su inmensidad trascienden la especificidad del tiempo y el espacio y, por lo tanto, abarcan desde emisiones en la atmósfera y los océanos, hasta el uso global de pesticidas en la industria agricultora de exportación. Son híper en cuánto no permiten una división clara entre lo global, lo local, y los cuerpos-organismos vivos e inertes. Más aún, estos hiperobjetos a los que se refiere Morton, emergen en un momento de crisis ecológica y climática, borrando fronteras materiales, espaciales y temporales. De este modo, a una naturaleza objetivada se suman ahora cuerpos objetivados, cuerpos expuestos, rociados, y vulnerados por estos hiperobjetos a través de un proceso que Rob Nixon (2011) definió, acertadamente, como de "violencia lenta". ${ }^{21}$ En un momento en que la misma noción de futuro se abre a especulación, cabe entonces preguntarse ¿cómo se inserta el cuerpo en este mapa donde la degradación ambiental se introduce como gusanos, un fenómeno inclasificable, un "Mal", por medio de una porosidad dérmica hasta transformar, la misma corporalidad, en una mutación? Enfermedades, deformidades, monstruosidades, aberraciones, otredades que emergen discursivamente, abarcando el espacio del mundo natural, dividiendo cuerpos sanos y enfermos e interpelando el antropocentrismo imperante. Frente a esta crisis ecológica que la modernidad ha desatado-y continúa haciéndolopropongo hablar de una crisis corporal, entendiendo que, como se ha argumentado en algunos trabajos provenientes del área de la nueva materialidad y la justicia ambiental, nuestro cuerpo constituye el primer medio ambiente (Ray \& Sibara, 2017).

Para concluir, me gustaría formular que los cuerpos receptores de una naturaleza devenida mero "recurso económico" consisten en metáforas horríficas y espectrales de la continua extracción-agricultora, minera, petrolera, floricultora, nuclear, entre muchas más-de un mundo natural que también se ha ido reconfigurando. En este sentido, es importante rescatar el concepto que desarrolla Rachel Carson de ecología del cuerpo humano, en cuanto punto de partida para reflexionar sobre la relación entre corporalidad y mundo natural. Para Carson, los cuerpos no constituyen límites; por el contrario, son vulnerables y se encuentran afectados por el uso global de químicos (agros o no), del mismo modo que el mundo humano y no humano. Y en este sentido, todas las formas de vida son más similares que disimiles (Lear, 2002, xvii).

\footnotetext{
${ }^{21}$ Pino Solanas definió esta agrupación de cuerpos en comunidades como "pueblos fumigados". Ver el documental que realizara antes de su muerte, en el año 2018: Viaje a los pueblos fumigados.
} 
Las novelas de Samanta Schweblin y Juan Diego Incardona, junto al poemario de Julián Joven, se definen como una escritura de prognosis, en cuanto pronostican, a través de una textualidad dérmica, las vertientes posibles de un devenir incierto. Textualidad dérmica en cuanto que, en su misma materialidad, plasma la toxicidad corpórea e inexpugnable que define y expone cuerpos variados (jóvenes y viejos, femeninos y masculinos, humanos y no humanos), degradándolos. Espectros corporales que devienen, a tal efecto, la frontera última de una contaminación agroquímica prolongada y sistemática. Sus escrituras reconfiguran, así, no sólo la relación del sujeto con su entorno "natural", sino que es el paisaje-como el mismo cuerpo-el que registra y documenta estas metamorfosis.

Cuerpos asediados por enfermedades (respiratorias, jaquecas, cáncer) e incapaces de reproducir, ya que abortan la idea misma de futuro. Cuerpos que, a pesar de ser inscritos en la previsibilidad del lenguaje, exacerban las especulaciones apocalípticas que la era del Antropoceno nos advierte y, por lo tanto, encarnan la aberración misma de una intervención humana en el marco más amplio de la historia. Cuerpos que poco a poco forman parte del nuevo paisaje rural argentino, y que, aunque silenciados e invisibilizados, se filtran en los surcos de nuestros imaginarios para instalarse, para invitarnos a reflexionar sobre el futuro, los posibles futuros, o el futuro del futuro.

Del campo a la ciudad y viceversa porque no hay afuera. Tanto el espacio rural como el urbano constituyen estéticas de la toxicidad, formas e imágenes de un continuum tóxico. Sin duda la crisis global climática es planetaria. Pero es, a su vez, una crisis cuya "violencia lenta", invisible e intangible, poco a poco nos envuelve, reemergiendo a través de un reparto y disposición inequitativos de nocividades, como así también por medio de la organización espaciotemporal de los cuerpos que allí se alojan. Una incidencia que, igual que la Intemperie, los gusanos, el fenómeno o el "Mal", se vale de una materialidad cuya vitalidad genera, como propuso Jane Bennett en Vibrant Matter (2011), corrientes vivas de químicos y partículas áreas que alteran (y mutan) nuestro alrededor, tornándonos irritantes (y agentes) de las mismas materias y los mismos desechos que vamos generando.

\section{Referencias}

Aboaf, C. (2016). El rey del agua. Buenos Aires, Argentina: Alfaguara.

Acosta, A. (2014). Prólogo. Los Derechos de la Naturaleza o el derecho a la existencia. En E. Gudynas., Derechos de la Naturaleza. Ética biocéntrica y políticas ambientales (pp.11-19). Lima, Perú: Programa Democracia y Transformación Global; Red Peruana por una Globalización con Equidad; CooperAcción / Montevideo: Centro Latino Americano de Ecología Social. 
Alaimo, S. (2016). Environmental Politics and Pleasures in Posthuman Times. Minneapolis, U.S.A.: University of Minnesota Press.

Almada, S. (2012). El viento que arrasa. Buenos Aires, Argentina: Mardulce.

Beck, U. (2004). Risk Society: Towards a New Modernity. London, U.K.: Thousand Oaks, New Delhi. Sage Publications.

Beilin, K. O. \& Suryanarayanan, S. (2017). The War Between Amaranth and Soy: Interspecies Resistance to Transgenic Soy Agriculture in Argentina. Environmental Humanities, 9, (2), pp. 204-229.

Bennett, J. (2010). Vibrant Matter. A Political Ecology of Things. Durham, Inglaterra: Duke University Press.

Bolívar, S. (1983). Decretos conservacionistas del Libertador. República de Venezuela: Ministerio del Ambiente y de los Recursos Naturales Renovables.

Buell, L. (1998). Toxic Discourse. Critical Inquiry, 24 (3) (Spring), pp. 639-665.

Cabezón Cámara, G. (2017). Las aventuras de la China Iron. Buenos Aires, Argentina: Penguin Random House.

Carson, R. (2002). Silent Spring. Boston, U.S.A.: Mariner Books.

Castree, N. (2013). Making Sense of Nature. Abingdon, UK: Routledge.

Contreras, S. (2011). Economías literarias en algunas ficciones argentinas del 2000 (Casas, Incardona, Cucurto y Mariano Llinás). Orbis Tertius, XVI (17), pp.1-14.

Cossío, D. (2020). What Have I Done to Deserve This? 'Abnormal' Motherhoods in 21stcentury Spanish and Argentinian Cultural Products (Tesis de doctorado). Universidad de Texas, Austin.

Dabove, J. P. \& Hallstead, S. (2012). Introducción. En P. Mairal. El año del desierto (vii-xxxiv). Doral, U.S.A.: Stockcero.

De Leone, L. (2017). Campos que matan. Espacios, tiempos y narración en Distancia de rescate de Samanta Schweblin. $452^{\circ} F$. Revista de Teoría de la literatura y Literatura Comparada, (16), pp. 62-76.

Eleisegui, P. (2017). Envenenados. Una bomba química nos extermina en silencio. Buenos Aires, Argentina: Gárgola.

French, J. \& Heffes, G. (2021). Nature and the Foundation of the Nation-States. En 
The Latin American Ecocultural Reader (pp. 81-86). Evanston, U.S.A.: Northwestern University Press.

Fritsch, K. (2017). Toxic Pregnancies: Speculative Futures, Disabling Environments, and Neoliberal Biocapital. En S.J. Ray \& J. Sibara, J. (Eds.). Disability Studies and the Environmental Humanities: Toward an Eco-Crip Theory (pp.359-380). Lincoln, Nebraska; London, England: University of Nebraska Press.

Fukuyama, F. (2002). Our Posthuman Future: Consequences of the Biotechnology Revolution. New York, U.S.A.: Farrar, Strauss, Giroux.

Grandjean, P. \& Landrigan, P. J. (2014). Neurobehavioural Effects of Developmental Toxicity.The Lancet Neurology, 13 (3), pp. 330-338.

Griswold, E. (2012). How 'Silent Spring' Ignited the Environmental Movement. The New York Times Magazine:

http://www.nytimes.com/2012/09/23/magazine/how--slent-springignited-the-environmental-movement.html. Acceso obtenido el 29 de enero, 2018.

Gudynas, E. (2014). Derechos de la Naturaleza. Ética biocéntrica y políticas ambientales. Lima:Programa Democracia y Transformación Global; Red Peruana por una Globalización con Equidad; CooperAcción / Montevideo: Centro Latino Americano de Ecología Social.

Güiraldes, R. (1926). Don Segundo Sombra. Buenos Aires, Argentina: Proa.

Haraway, D. (1991). Simians, Cyborgs, and Women: The Reinvention of Nature. New York, U.S.A.: Routledge.

Haraway, D. (2003). The Companion Species Manifesto: Dogs, People, and Significant Otherness.Chicago, U.S.A.: Prickly Paradigm Press.

Haraway, D. (2007). When Species Meet. Minneapolis, U.S.A.: University of Minnesota Press.

Harwicz, A. (2012). Mátate, amor. Madrid, España: Lengua de trapo.

Heise, U. K. (2008). Sense of Place and Sense of Planet: The Environmental Imagination of the Global. New York, U.S.A.: Oxford University Press.

Heywood, P. (2017). The Ontological Turn. En F. Stein, S. Lazar, M. Candea, H. Diemberger, J. Robbins, A. Sanchez \& R. Stasch. (Eds.). The Cambridge Encyclopedia of Anthropology (pp.xx-xx). http://doi.org/10.29164/17ontology

Incardona, J. D. (2007). El ataque a Villa Celina. Buenos Aires: Libros de Eloisa 
Cartonera.

Incardona, J. D. (2008). Villa Celina. Buenos Aires, Argentina: Grupo Editorial Norma.

Incardona, J. D. (2009). El campito. Buenos Aires, Argentina: Mondadori.

Incardona, J. D. (2010). Rock barrial. Buenos Aires, Argentina: Grupo Editorial Norma.

Incardona, J. D.(2016a). Las estrellas federales. Buenos Aires, Argentina: Interzona.

Incardona, J. D.(2016b). "Hoy estamos nuevamente en una época de mutaciones", Página 12 (17 de octubre):

https://www.pagina12.com.ar/diario/suplementos/espectaculos/4-

40309-2016-10-17.html. Acceso obtenido el 1 de febrero de 2021.

Joven, J. [Cristian Molina]. (2014a). Un pequeño mundo enfermo. Mar del Plata, Argentina: La bola editora.

Joven, J. (2014b). Esa idea de Deleuze del escritor como médico, Télam. Agencia Nacional de Noticias (9 de septiembre):

https://www.telam.com.ar/notas/201409/77534-esa-idea-de-deleuze-delescritor-como-medico.php. Acceso obtenido el 2 de febrero de 2021.

Krimer, M. I. (2011). La inauguración. Buenos Aires, Argentina: Editorial El Ateneo.

Lapegna, P. (2016). Soybeans and Power: Genetically Modified Crops, Environmental Politics, and Social Movements in Argentina. New York, U.S.A.: Oxford University Press.

Latour, B. (1993). We Have Never Been Modern. Trans. C. Porter. Cambridge, MA: Harvard University Press.

Latour, B. (2004). Politics of Nature: How to Bring the Sciences into Democracy. Cambridge, MA, U.S.A.: Harvard University Press.

Lear, L. (2002). Introduction. En R. Carson, Silent Spring (pp.x-xx). Boston, U.S.A.: Mariner Books.

Lefebvre, H. (1974). La production de l'espace. Paris, Francia: Anthropos.

Ludmer, J. (2004). Territorios del presente - En la isla urbana. Pensamiento de los confines (15), pp.103-110.

Lugones, L. (1996). "La lluvia de fuego”. En Las fuerzas extrañas (pp.xx-xx). Madrid, España: Cátedra. 
Mairal, P. (2005). El año del desierto. Buenos Aires, Argentina: Interzona.

Martínez Alier, J. (2002). The Environmentalism of the Poor. A Study of Ecological Conflicts and Valuation. Northhampton, MA, U.S.A.: Edward Elgar Publishing.

Massuh, G. (2012). La omisión. Buenos Aires, Argentina: Adriana Hidalgo.

Massuh, G. (2015). Desmonte. Buenos Aires, Argentina: Adriana Hidalgo.

McKibben, B. (1989). The End of Nature. New York, U.S.A.: Anchor Books.

Morton, T. (2007). Ecology Without Nature: Rethinking Environmental Aesthetics. Cambridge, MA, U.S.A. Harvard University Press.

Morton, T. (2010). The Ecological Thought. Cambridge, MA, U.S.A.: Harvard University Press.

Morton, T. (2013). Hyperobjects: Philosophy and Ecology after the End of the World. Minneapolis, U.S.A.: University of Minnesota Press.

Nixon, R. (2011). Slow Violence and the Environmentalism of the Poor. Cambridge, MA, U.S.A: Harvard University Press.

Petryna, A. (2002). Life Exposed: Biological Citizens After Chernobyl. Princeton: Princeton, U.S.A.: University Press.

Ray, S. J. \& Sibara, J. (Eds.). (2017). Disability Studies and the Environmental Humanities: Toward an Eco-Crip Theory. Lincoln, Nebraska; London, England: University of Nebraska Press.

Rodríguez, F. (2019). El giro rústico: el nuevo campo argentino. En I. Depetris Chauvin \& M. Urzua Opazo. (Eds.), Más allá de la naturaleza. Poéticas y configuraciones espaciales en la cultura latinoamericana contemporánea (pp.183-208). Santiago de Chile, Chile: Ediciones Universidad Alberto Hurtado.

Rodríguez, N. (2013). La vi mutar. Buenos Aires, Argentina: Editorial Wu Wei.

Romero, I. (2014). Las hamacas de Firmat. Rosario, Argentina: Editorial Municipal de Rosario.

Ross, A. (1995). The Chicago Gangster Theory of Life: Nature's Debt to Society. London, U.K.: Verso.

Ross, A. (2011). Bird on Fire: Lessons from the World's Least Sustainable City. New York, U.S.A.: Oxford University Press. 
Sarmiento, D. F. (1988). Facundo: civilización y barbarie. Madrid, España: Alianza Editorial.

Schweblin, S. (2014). Distancia de rescate. Barcelona, España: Literatura Random House.

Smith, N. (1984). Uneven Development. Oxford, UK: Blackwell.

Solanas, P. (2018). Viaje a los pueblos fumigados. Argentina: Cinesur.

Soldati, C. (2015). The Human Cost of Agrotoxins, Pablo Ernesto Piovano's photo feature, is now a book. Lifegate (11 de noviembre): https://www.lifegate.com/the-human-cost-of-agrotoxins-glyphosate. (Acceso obtenido el 2 de febrero de 2021).

Taylor, S. (2019). Disabled Ecologies: Living with Impaired Landscapes. The Othering and Belonging Institute at UC Berkeley. https://belonging.berkeley.edu/video-sunaura-taylor-disabled-ecologiesliving-impaired-landscapes. Acceso obtenido el 2 de febrero de 2021.

Truitt Nakata, G. (2019). Monocultivos: la amenaza de los 'desiertos verdes' de hoy para la producción alimentaria de mañana (28 de febrero). The Nature Conservancy:https://www.nature.org/es-us/que-hacemos/nuestravision/perspectivas/monocultivos-amenaza-desiertos-verdes-produccionalimentaria/. Acceso obtenido el 1 de febrero de 2021.

Tsing, A. (2012). Unruly Edges: Mushrooms as Companion Species. Environmental Humanities 1, (1), pp. 141-154.

Williams, R. (1973). The Country and the City. New York, U.S.A.: Oxford University Press.

Williams, R. (1980). Ideas of Nature. Problems in Materialism and Culture (pp.67-85). London, U.K.: Verso.

Wulf, A. (2017). The Invention of Nature. Alexandrer Von Humboldt's New World. New York, U.S.A: Alfred A. Knopf. 